\title{
Diet Induced Modifications of Fatty-Acid Composition in Mealworm Larvae (Tenebrio molitor)
}

\author{
Nicolas Jean Fasel ${ }^{1,2}$, Laurent Mène-Saffrané ${ }^{3}$, Ireneusz Ruczyński ${ }^{4}$, Ewa Komar ${ }^{4}, \&$ Philippe Christe $^{2}$ \\ ${ }^{1}$ Leibniz Institute for Zoo and Wildlife Research, Berlin, Germany \\ ${ }^{2}$ Department of Ecology and Evolution, University of Lausanne, Lausanne, Switzerland \\ ${ }^{3}$ Department of Biology, University of Fribourg, Chemin du musée 10, Fribourg, Switzerland \\ ${ }^{4}$ Mammal Research Institute Polish Academy of Science, Białowieża, Poland \\ Correspondence: Nicolas Jean Fasel, Leibniz Institute for Zoo and Wildlife Research, Berlin, Germany, \\ Switzerland. Tel: 41-793-608-036. E-mail: fasel.nicolas@gmail.com,
}

\author{
Received: May 16, $2017 \quad$ Accepted: June 30, $2017 \quad$ Online Published: August 8, 2017 \\ doi:10.5539/jfr.v6n5p22 URL: https://doi.org/10.5539/jfr.v6n5p22
}

\begin{abstract}
The diet of Western human societies is characterized by an excess of saturated fatty acids (FAs) and a high concentration of $\omega-6$ relative to $\omega-3$ polyunsaturated FA (PUFA). These unbalanced diets are suspected to trigger diseases and disorders. To alleviate this public health concern, the production of healthier meat with more PUFAs of higher $\omega-3$ concentration could potentially be achieved by modifying livestock diets. The high nutritional value and limited breeding costs of edible insects have brought insect feed into the discussion as a promising fat source for animal and human diets. In this study, we sought to increase the amount of $\omega$-3 PUFAs in mealworm (Tenebrio molitor) larvae. We investigated the effects of diets varying in $\omega-3 / \omega-6$ ratio and FA concentration but similar in PUFA proportion on larva FA composition. Mealworm larvae showed significant plasticity in lipid composition. High dietary $\omega-3 / \omega-6$ ratios induced an increase in the proportion of $\omega-3$ and a decrease in $\omega-6$, which resulted in higher larval $\omega-3 / \omega-6$ ratios, but also in higher larval PUFA proportion. Increasing FA concentrations in larva diets also favored the accumulation of PUFAs to the detriment of monounsaturated and saturated FAs. Providing $\omega$-3-rich seeds to mealworm larvae could allow the production of economical animal fat with healthier PUFA percentages $(>60 \%)$ and $\omega-3 / \omega-6$ ratios $(>0.5)$.
\end{abstract}

Keywords: flax seed, gaz chromatography, lipid, polyunsaturated fatty acids, walnuts

\section{Introduction}

The biochemical and biophysical characteristics of PUFAs are crucial for animal physiology. PUFAs influence cellular membrane fluidity, functions, signaling and expression (Jump, 2002). They play essential roles in brain functioning (Bradbury, 2011; Uauy, Hoffman, Peirano, Birch, \& Birch, 2001), whole body metabolism (Arnold, Giroud, Valencak, \& Ruf, 2015; Geiser \& Kenagy, 1987; Hulbert, 2010; McGuire, Fenton, \& Guglielmo, 2013; Munro \& Thomas, 2004), muscular performance (Valencak, Arnold, Tataruch, \& Ruf, 2003), immunity (Stanley \& Miller, 2006; Stanley-Samuelson et al., 1991; Ziboh, Miller, \& Cho, 2000) and reproduction (Fair, Doyle, Diskin, Hennessy, \& Kenny, 2014; Rahman, Gasparini, Turchini, \& Evans, 2014; Safarinejad, Hosseini, Dadkhah, \& Asgari, 2010; Strzeżek, Fraser, Kuklińska, Dziekońska, \& Lecewicz, 2004; Zalata, Christophe, Depuydt, Schoonjans, \& Comhaire, 1998). Animal species use a combination of desaturases and elongases to

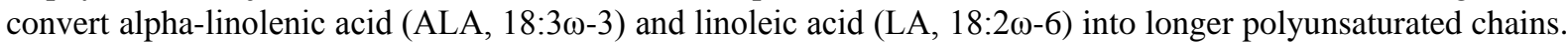
However, they generally cannot introduce a double bond beyond the carbon 9 to synthetize ALA and LA de novo (G. Burr \& M. Burr, 1930; Sinclair, 1984). These essential fatty acids (FAs) are transferred from leaves, seeds, or phytoplankton to higher trophic levels through the food chain (Budge, Iverson, \& Koopman, 2006). A few insect species are exceptions as they produce delta12-desaturase and can convert oleic acid into LA (Brandstetter \& Ruther, 2016; Cripps, Blomquist, \& de Renobales, 1986; Zhou et al., 2008).

In Western societies, industrial food is characterized by an excess of saturated and trans FAs and high concentration of $\omega-6$ relative to $\omega-3$ PUFAs (Cordain et al., 2005; Simopoulos, 1999; 2002). These unbalanced diets are suspected to trigger several diseases and disorders. Indeed, the supplementation in dietary $\omega-3$ appears to reduce the risk of coronary heart disease (Bucher, Hengstler, Schindler, \& Meier, 2002; Harper \& Jacobson, 
2003), improve infant neurological development (Daniels, Longnecker, Rowland, \& Golding, 2004; Jørgensen, Hernell, Hughes, \& Michaelsen, 2001), and attenuate depression (Mischoulon \& Fava, 2000) or behavioral disorders (Freeman, 2000). Dietary $\omega-3$ supplementation was also shown to improve ejaculate quality in humans and animals (Attaman et al., 2012; Estienne, Harper, \& Crawford, 2008; Mourvaki, Cardinali, Bosco, Corazzi, \& Castellini, 2010).

An adaptation of the dietary lipid composition of productive livestock is expected to produce healthier meat with more PUFAs of higher $\omega-3$ concentration (Komprda, Zorníková, Rozíková, Borkovcová, \& Przywarová, 2013; Wood et al., 2004). Edible insects represent a minor but important food source in some countries (Chakravorty, Ghosh, \& Meyer-Rochow, 2011; Halloran \& Vantomme, 2013; Meyer-Rochow \& Changkija, 1997; Yang, Siriamornpun, \& $\mathrm{Li}, 2006)$. Due to high nutritional values and limited breeding costs, edible insects have emerged as a promising fat and protein source for animal and human diets (Belluco et al., 2013; Mlcek, Rop, Borkovcová, \& Bednarova, 2014; Nowak, Persijn, Rittenschober, \& Charrondiere, 2016; Rumpold \& Schlüter, 2013a; 2013b). In this emerging landscape, Switzerland's government played a pioneering role in 2017 by changing its legislation to authorize the production and commercialization of three insect species for human consumption, including the mealworm (Tenebrio molitor).

In this study, we aimed to induce a change in the lipid composition of mealworm (Tenebrio molitor) larvae, whose mass is made up of approximately $40 \%$ fat (Rumpold \& Schlüter, 2013a). This coleopteran species has already been reared for captive insectivorous species and human consumption, and is not known to produce delta12-desaturase (Cripps et al., 1986). We therefore investigated experimentally the effects of diets varying in $\omega-3 / \omega-6$ ratio and FA concentration but similar in PUFA proportion on the total larva fatty acid (FA) composition. Animal fodder richer in $\omega-3$ require stronger antioxidant protection and should be more expensive to produce and store than traditional food. It may thus be economically interesting to limit their provision to the larvae. We therefore conducted a short-term experiment on large larvae, to mimic a final fattening prior to harvesting. As insect larvae rapidly incorporate dietary lipids in fat reserves (Arrese \& Soulages, 2010; Canavoso, Jouni, Karnas, Pennington, \& Wells, 2001), we predicted that a change in the dietary $\omega-3 / \omega-6$ ratio should trigger a modification of the larval $\omega-3 / \omega-6$ ratio. Furthermore, if larvae assimilate identically both $\omega-3$ and $\omega-6$ FAs, their PUFA proportions should not change.

\section{Material and Methods}

\subsection{Experimental Setup}

The experiment took place in March 2016 at the Mammal Research Institute of the Polish Academy of Sciences (Białowieza). Mealworm (Tenebrio molitor) larvae were purchased from Agriopeterra (Daniel Puchalski, Białystok, Poland), and 160 larvae were placed in different boxes (20 per box) containing each 10g (ab libitum) of one of four different feeding regimes (two replicates conducted simultaneously, Table 1). Boxes were kept at room temperature $\left(\sim 23^{\circ} \mathrm{C}\right)$ and humidity $(\sim 30 \%)$. The food treatment were prepared to contain varying $\omega-3 / \omega-6$ ratios and FA concentrations but with relatively similar PUFA proportions (table 1). We prepared mixes of wheat flour, ground walnuts and flax seeds (table 1). Values of expected lipid concentrations and compositions of the ingredients were obtained from the USDA National Nutrient Database (ndb.nal.usda.gov). The food preparation were mixed homogenously. Five larvae were collected on day 0 as control. Three mealworm larvae per diet and replicate were sampled at days 3, 6 and 9 . Larvae were stored at $-80^{\circ} \mathrm{C}$ or kept on dry ice during shipment until analysis, and weighed before lipid extraction.

Table 1. Details of the different diets. Flax seeds (FS), walnuts (WN) and wheat floor (WF) expressed as percentage of the total mix mass. Expected (E) and measured (M) $\omega-3 / \omega-6$-ratios, PUFA proportion and FA concentration (\% of the mass)

\begin{tabular}{cccccccccc}
\hline Diet & FS & WN & WF & $\boldsymbol{\omega} \mathbf{\omega - 3 / \omega - 6 ~ E}$ & $\boldsymbol{\omega - 3 / ( \omega - 6 ~ M ~}$ & PUFA E & PUFA M & FA E & FA M \\
\hline A & 72 & 12 & 16 & 2 & 2.1 & 0.73 & 0.71 & 36.3 & 25.1 \\
B & 0.4 & 19.2 & 80.4 & 0.2 & 0.4 & 0.75 & 0.76 & 12.6 & 19.8 \\
C & 96 & 2 & 2 & 3.4 & 3 & 0.72 & 0.87 & 39.6 & 22.2 \\
D & 0 & 0 & 100 & 0.1 & 0.1 & 0.66 & 0.77 & 0.6 & 0.6 \\
\hline
\end{tabular}

\subsection{Lipid Extraction}

The entire mealworm larvae and $100 \mathrm{mg}$ of food mixture were ground in liquid nitrogen. The resulting powder sample was then mixed in $450 \mu \mathrm{L} \mathrm{MeOH}-\mathrm{CHCl}^{3}(2 / 1, \mathrm{v} / \mathrm{v})$ solution containing $0.1 \%(\mathrm{w} / \mathrm{v})$ of butylated hydroxytoluene (BHT, antioxidant), shaken for $15 \mathrm{~min}$, and briefly spun down. Then, $300 \mu \mathrm{L}$ of $\mathrm{H}_{2} 0$ and $150 \mu \mathrm{L}$ of $\mathrm{CHCl}_{3}$ were added to the mixture. The samples were further shaken for $5 \mathrm{~min}$, centrifuged at $3500 \mathrm{rpm}$ for 5 
min and briefly spun down. Infranatant phase was collected and transferred to a collector tube. A $150 \mu \mathrm{L}$ of $\mathrm{CHCl}_{3}$ was added to the samples, which were further shaken for $5 \mathrm{~min}$, centrifuged at $3500 \mathrm{rpm}$ for $5 \mathrm{~min}$ and briefly spun down. This step was performed twice and the infranatant phases were collected and placed in the collector tube each time. Finally, the sample lipid extracts were dried at $35^{\circ} \mathrm{C}$ under nitrogen flow, and resuspended in $50 \mu \mathrm{L}$ of $\mathrm{BHT}$ in $\mathrm{MeOH} 0.1 \%(\mathrm{w} / \mathrm{v})$.

\subsection{Preparation of FAMEs}

FAMEs were prepared by incubating solvent-extracted lipid extracts with $1 \mathrm{~mL}$ of $5 \%(\mathrm{v} / \mathrm{v}) \mathrm{H}_{2} \mathrm{SO}_{4}$ in $\mathrm{MeOH}$ in presence of $0.1 \%(\mathrm{w} / \mathrm{v})$ BHT. The transesterification reaction was performed in a dry block heater (VWR, Dietikon, Switzerland) set at $85^{\circ} \mathrm{C}$ for $30 \mathrm{~min}$. At the end of the reaction, tubes were cooled down to room temperature, briefly spun down, and $1.5 \mathrm{~mL}$ of $0.9 \%$ (w/v) $\mathrm{NaCl}$ and $2 \mathrm{~mL}$ of $n$-hexane were added to the reaction. The mixture was strongly shaken for $5 \mathrm{~min}$ and both organic and hydroalcoholic phases were separated by centrifugation at $1500 \mathrm{~g}$ for $5 \mathrm{~min}$. The upper organic ( $n$-hexane) phase was transferred into a new glass tube and $n$-hexane extraction was repeated two additional times on the hydroalcoholic phase. Combined $n$-hexane phases (approx. $6 \mathrm{~mL}$ in total) were evaporated under a nitrogen flux and FAMEs were resuspended in $2 \mathrm{~mL}$ of $n$-hexane. FAME samples were transferred into $0.2 \mathrm{~mL}$ crimp vials (BGB Analytik, Genève, Switzerland) prior to injection.

\subsection{GC- flame Ionization Detector (FID) Analysis of FAMEs.}

FAMEs were analyzed by GC coupled to FID (Agilent 7890A). FAME samples dissolved into $n$-hexane were introduced to the injection port heated at $250^{\circ} \mathrm{C}$ with an automated liquid sampler (Agilent 7993). The split injection ratio was 100:1. FAMEs were separated on 30-m long x 0.25 -mm ID x $0.25 \mu \mathrm{m}$ DB-23 capillary column (Agilent) using $\mathrm{He}$ as vector gas $(2.6 \mathrm{~mL} / \mathrm{min})$. The oven temperature, initially set at $100^{\circ} \mathrm{C}$ for $2 \mathrm{~min}$, was first increased to $160^{\circ} \mathrm{C}$ at $25^{\circ} \mathrm{C} / \mathrm{min}$, then to $250^{\circ} \mathrm{C}$ at $8^{\circ} \mathrm{C} / \mathrm{min}$ and maintained at this temperature for an additional $4 \mathrm{~min}$. The detector temperature was set at $270^{\circ} \mathrm{C}$ while detector gases were set at $30 \mathrm{~mL} / \mathrm{min}$ for $\mathrm{H}_{2}$, $400 \mathrm{~mL} / \mathrm{min}$ for air, and $30 \mathrm{~mL} / \mathrm{min}$ for makeup gas $(\mathrm{He})$. Data were recorded at a frequency of $50 \mathrm{~Hz}$. FAME quantifications were performed with calibration curves built with the Supelco 37 component FAME mix (Sigma) using 17:0 methyl ester as the internal standard. Only fatty acids represented more than $1 \%$ of the total fatty acid mass were considered.

\subsection{Statistical Analyses}

Statistical analyses were performed with R (3.2.3). The significance level was set at 5\%. Individual larva FAs were categorised as $\omega-6$ or $\omega-3$ PUFA, monounsaturated FA (MUFA) or saturated FA (SFA).

The effects of the food treatments in interaction with the experiment duration were tested on the FA compositions with a multivariate analysis. The concentrations of the different FA categories were classified as closed compositions with the function "acomp" (package: compositions, Van den Boogaart, Tolosana, \& Bren, 2014) and transformed with isometric log-ratio (function "ilr", package: compositions, Van den Boogaart et al., 2014). A linear model (function "lm") was run and the F- and P-values were calculated with the "anova" function.

Additionnally, the effects of the measured dietary $\omega-3 / \omega-6$ ratio (log-transformed) and FA concentrations (centred and normalized), in interaction with experiment duration were evaluated on the larval FA compositions. Similarly to the above description, the different FA categories, classified as compositions, were considered as response variables in a linear model (function "lm"). Then, the effects of measured dietary $\omega-3 / \omega-6$ ratios and FA concentrations (same transformations than above) on the proportions of the various FA categories (amount of FAs of one category over all FAs, logit transformed, function "logit", package: car, Fox \& Weisberg, 2011) were evaluated with univariate analyses. The proportion of PUFAs (proportions of $\omega-3$ and $\omega-6$ combined, logit-transformed) and the $\omega-3 / \omega-6$ ratio (increased by one and log-transformed) of the larvae were finally analysed with univariate analyses. The F- and P-values were calculated with the "anova" function for the multivariate analysis and with ANOVA type III for the univariate analyses (function "Anova", package: car, Fox \& Weisberg, 2011). Non-significant interactions were removed (Engqvist, 2005; Van den Boogaart \& Tolosana-Delgado, 2013). The values from the five mealworms collected as control were used as the values on day 0 for the different diets. In order to interpret the effects of the diet's explanatory variables alone and in interaction with experiment duration, we moved the intercept to the last day of experiment by subtracting 9 days (length of the experiment) from the experiment's duration.

\section{Results}

The larval FA compositions were significantly changed by the different treatments in the course of the 
experiment (table 2A). The changes in FA compositions were further significantly related to the measured dietary $\omega-3 / \omega-6$ ratio and FA concentrations and to the interaction between the dietary $\omega-3 / \omega-6$ ratio and the experiment duration (table $2 \mathrm{~B}$ ). The interaction between the measured dietary FA concentration and the experiment duration did not show any significant effects (table 2B).

With a dietary $\omega-3 / \omega-6$ ratio equal to 1 , the model predicts an increase in the $\omega-3$ proportion and in the $\omega-3 / \omega-6$ ratio during the experiment, but without significant changes in proportions of $\omega-6$, MUFA, SFA and PUFA (table 3 ). An increase in dietary $\omega-3 / \omega-6$ ratio alone (i.e. at the end of the experiment) led to a significant increase in the proportions of $\omega-3$ and PUFAs, and in the $\omega-3 / \omega-6$ ratio of the larvae. At the same time, an increase in dietary $\omega-3 / \omega-6$ ratio was significantly related to a decrease in the proportions of $\omega-6$, MUFAs and SFAs (table 3 ). The dietary FA concentration was negatively correlated with the proportions of MUFAs and SFAs in the larvae, but positively correlated with the larval proportions of PUFAs. However, the dietary FA concentration impacted neither the proportions of $\omega-6$ and $\omega-3$ nor the the $\omega-3 / \omega-6$ ratio of the larvae (table 3 ). The interactions between the dietary FA concentrations and the experiment duration never showed any significant effects (table 3 ). FA concentrations and compositions of larvae and diets are reported in table 4.

Table 2. Analyses of the effects of the treatments in interaction with the experiment duration (A), and of the dietary $\omega-3 / \omega-6$ ratio in interaction with the experiment duration and of the measured dietary FA concentrations (B) on the larval FA composition. Models' Pillai's values with approximate F-values, degrees of freedom (DF) and P-values (P). In italics, non-significant interaction, removed from model

\begin{tabular}{|c|c|c|c|c|}
\hline A & Pillai & Approx. F & DF & $\mathbf{P}$ \\
\hline Intercept & 0.986 & 1744.92 & 1,73 & $<0.001$ \\
\hline Experiment duration & 0.319 & 11.07 & 1,73 & $<0.001$ \\
\hline Treatments & 0.759 & 8.24 & 3,73 & $<0.001$ \\
\hline $\begin{array}{l}\text { Exp duration : Treatments } \\
\text { B }\end{array}$ & 0.408 & 3.83 & 3,73 & $<0.001$ \\
\hline Intercept & 0.986 & 1738.38 & 1,76 & $<0.001$ \\
\hline Experiment duration & 0.315 & 11.35 & 1,76 & $<0.001$ \\
\hline$\omega 3 / \omega 6$-ratio & 0.657 & 47.33 & 1,76 & $<0.001$ \\
\hline FA concentration & 0.253 & 8.36 & 1,76 & $<0.001$ \\
\hline Exp duration : $\omega 3 / \omega 6$-ratio & 0.365 & 14.15 & 1,76 & $<0.001$ \\
\hline Exp duration : FA concentration & 0.012 & 0.28 & 1,75 & 0.8375 \\
\hline
\end{tabular}


Table 3. Analyses of the effects of the dietary $\omega-3 / \omega-6$ ratio in interaction with the experiment duration and of the measured dietary FA concentrations on the various larval FA categories and the $\omega-3 / \omega-6$ ratio . Models' estimates and standard error (SE) with the F-values (F), degrees of freedom (DF) and P-values (P). In italics, non-significant interactions, removed from model

\begin{tabular}{|c|c|c|c|c|c|}
\hline Proportion $\omega-3$ & Estimate & SE & $\mathbf{F}$ & DF & $\mathbf{P}$ \\
\hline Intercept & -1.70 & 0.11 & 232.19 & 1,76 & $<0.001$ \\
\hline Experiment duration & 0.12 & $1.91 * 10^{-2}$ & 42.09 & 1,76 & $<0.001$ \\
\hline$\omega-3 / \omega-6$ ratio & 0.49 & 0.12 & 18.11 & 1,76 & $<0.001$ \\
\hline FA concentration & 0.28 & 0.16 & 3.28 & 1,76 & 0.074 \\
\hline Exp duration : $\omega-3 / \omega-6$ ratio & $6.72 * 10^{-2}$ & $1.21 * 10^{-2}$ & 30.73 & 1,76 & $<0.001$ \\
\hline $\begin{array}{l}\text { Exp duration : FA concentration } \\
\text { Proportion } \boldsymbol{\omega - 6}\end{array}$ & $-4.26 * 10^{-3}$ & $4.46 * 10^{-2}$ & 0.01 & 1,75 & 0.924 \\
\hline Intercept & -0.602 & $1.21 * 10^{-3}$ & $9.11 * 10^{6}$ & 1,76 & $<0.001$ \\
\hline Experiment duration & $-4.07 * 10^{-2}$ & $2.07 * 10^{-4}$ & 0.43 & 1,76 & 0.511 \\
\hline$\omega-3 / \omega-6$ ratio & $-5.02 * 10^{-2}$ & $1.25^{*} 10^{-3}$ & 12.25 & 1,76 & 0.001 \\
\hline FA concentration & 0.38 & $1.69 * 10^{-3}$ & 2.64 & 1,76 & 0.108 \\
\hline Exp duration : $\omega-3 / \omega-6$-ratio & $3.40 * 10^{-4}$ & $1.32 * 10^{-4}$ & 6.69 & 1,76 & 0.012 \\
\hline $\begin{array}{l}\text { Exp duration : FA concentration } \\
\text { Proportion MUFA }\end{array}$ & $3.85 * 10^{-2}$ & $2.42 * 10^{-2}$ & 2.52 & 1,75 & 0.116 \\
\hline Intercept & -0.80 & $6.53 * 10^{-2}$ & 150.51 & 1,76 & $<0.001$ \\
\hline Experiment duration & $-1.95 * 10^{-2}$ & $1.12 * 10^{-2}$ & 3.06 & 1,76 & 0.084 \\
\hline$\omega-3 / \omega-6$ ratio & -0.16 & $6.72 * 10^{-2}$ & 5.58 & 1,76 & 0.021 \\
\hline FA concentration & -0.31 & $9.09 * 10^{-2}$ & 11.30 & 1,76 & 0.001 \\
\hline Exp duration : $\omega-3 / \omega-6$ ratio & $-3.63 * 10^{-2}$ & $7.09 * 10^{-3}$ & 26.24 & 1,76 & $<0.001$ \\
\hline $\begin{array}{l}\text { Exp duration : FA concentration } \\
\text { Proportion SFA }\end{array}$ & $6.14 * 10^{-3}$ & $2.61 * 10^{-2}$ & 0.06 & 1,75 & 0.814 \\
\hline Intercept & -1.75 & $2.79 * 10^{-2}$ & $3.98 * 10^{3}$ & 1,76 & $<0.001$ \\
\hline Experiment duration & $-3.04 * 10^{-3}$ & $4.76^{*} 10^{-3}$ & 0.41 & 1,76 & 0.525 \\
\hline$\omega-3 / \omega-6$ ratio & -0.12 & $2.87 * 10^{-2}$ & 18.85 & 1,76 & $<0.001$ \\
\hline FA concentration & -0.13 & $3.88 * 10^{-2}$ & 11.57 & 1,76 & 0.001 \\
\hline Exp duration : $\omega-3 / \omega-6$ ratio & $-2.03 * 10^{-2}$ & $3.03 * 10^{-3}$ & 45.29 & 1,76 & $<0.001$ \\
\hline $\begin{array}{l}\text { Exp duration : FA concentration } \\
\text { Proportion PUFA }\end{array}$ & $-4.02 * 10^{-3}$ & $1.11 * 10^{-2}$ & 0.13 & 1,75 & 0.719 \\
\hline Intercept & 0.10 & $6.95 * 10^{-2}$ & 2.14 & 1,76 & 0.148 \\
\hline Experiment duration & $1.45 * 10^{-2}$ & $1.19 * 10^{-2}$ & 1.48 & 1,76 & 0.227 \\
\hline$\omega-3 / \omega-6$ ratio & 0.22 & $7.16^{*} 10^{-2}$ & 9.21 & 1,76 & 0.003 \\
\hline FA concentration & 0.39 & $9.67 * 10^{-2}$ & 16.09 & 1,76 & $<0.001$ \\
\hline Exp duration : $\omega-3 / \omega-6$ ratio & $4.69 * 10^{-2}$ & $7.59 * 10^{-3}$ & 38.59 & 1,76 & $<0.001$ \\
\hline $\begin{array}{l}\text { Exp duration : FA concentration } \\
\boldsymbol{\omega - 3 / \omega - 6} \text { ratio }\end{array}$ & $1.79 * 10^{-2}$ & $2.77 * 10^{-2}$ & 0.42 & 1,75 & 0.520 \\
\hline Intercept & 0.35 & $2.22 * 10^{-2}$ & 245.16 & 1,76 & $<0.001$ \\
\hline Experiment duration & $2.69 * 10^{-2}$ & $3.80 * 10^{-3}$ & 50.21 & 1,76 & $<0.001$ \\
\hline$\omega-3 / \omega-6$ ratio & 0.14 & $2.29 * 10^{-2}$ & 35.61 & 1,76 & $<0.001$ \\
\hline FA concentration & $-1.10 * 10^{-2}$ & $3.10 * 10^{-2}$ & 0.13 & 1,76 & 0.724 \\
\hline Exp duration : $\omega-3 / \omega-6$ ratio & $1.36^{*} 10^{-2}$ & $2.42 * 10^{-3}$ & 31.71 & 1,76 & $<0.001$ \\
\hline Exp duration : FA concentration & $98.79 * 10^{-3}$ & $8.83 * 10^{-3}$ & 1.23 & 1,75 & 0.271 \\
\hline
\end{tabular}

Table 4. Means and standard errors of body masses (BM, mg), fatty acid compositions (percentage of the total fatty acid mass), $\omega-3 / \omega-6$ PUFA ratios and PUFA proportions among the different days and diets

\begin{tabular}{|c|c|c|c|c|c|c|c|c|c|c|}
\hline Diets & days & BM & 16:0 & 16:1 & 18:0 & 18:1 & 18:2 & $18: 3$ & $\begin{array}{c}\omega-3 / \\
\omega-6 \text { ratio }\end{array}$ & $\begin{array}{c}\text { PUFA } \\
\text { proportion }\end{array}$ \\
\hline NA & 0 & $53.44 \pm 16.76$ & $9.56 \pm 0.73$ & $0.70 \pm 0.66$ & $5.38 \pm 1.32$ & $32.45 \pm 7.58$ & $48.00 \pm 7.45$ & $3.91 \pm 4.68$ & $0.08 \pm 0.10$ & $0.52 \pm 0.08$ \\
\hline A & 3 & $72.14 \pm 18.57$ & $9.69 \pm 2.37$ & $86 \pm 0.44$ & $3.71 \pm 0.58$ & $30.66 \pm 10.35$ & $42.43 \pm 9.83$ & $12.64 \pm 6.46$ & $0.31 \pm 0.17$ & $0.55 \pm 0.13$ \\
\hline B & 3 & $96.00 \pm 19.38$ & $9.29 \pm 0.98$ & $0.65 \pm 0.36$ & $3.55 \pm 0.40$ & $24.21 \pm 4.12$ & $51.83 \pm 4.03$ & $10.48 \pm 1.52$ & $0.20 \pm 0.02$ & $0.62 \pm 0.05$ \\
\hline $\mathrm{C}$ & 3 & $81.44 \pm 12.46$ & $10.21 \pm 1.11$ & $1.44 \pm 0.79$ & $4.21 \pm 0.63$ & $32.72 \pm 5.31$ & $39.13 \pm 5.58$ & $12.29 \pm$ & $0.33 \pm 0.25$ & $0.51 \pm 0.06$ \\
\hline D & 3 & $97.25 \pm 12.27$ & $15.80 \pm 1.40$ & $2.07 \pm 0.50$ & $4.01 \pm 0$ & $46.38 \pm$ & $44 \pm 4.63$ & $130+$ & $0.04 \pm 0.03$ & $0.32 \pm 0.06$ \\
\hline A & 6 & $84.54 \pm 17.60$ & $750+097$ & & & & & 22. & & \\
\hline B & 6 & 81.1 & $12.47 \pm$ & & & & & & & \\
\hline $\mathrm{C}$ & 6 & & & & & & & 15.16 & & \\
\hline D & 6 & & 16.7 & & & 47. & & 1.20 & & 0.25 \\
\hline A & 9 & & & & 4.2 & & & 21. & 29 & 0.66 \\
\hline B & 9 & .83 & 11.97 & .34 & $4.18 \pm 0.50$ & 85 & .89 & 82 & $0.16 \pm 0.04$ & $0.49 \pm 0.11$ \\
\hline $\mathrm{C}$ & 9 & $53.74 \pm 24.55$ & $7.79 \pm 1.08$ & $0.37 \pm 0.24$ & $5.33 \pm 1.22$ & $25.10 \pm 3.58$ & $37.48 \pm 5.67$ & $23.93 \pm 4.94$ & $0.66 \pm 0.23$ & $0.61 \pm 0.04$ \\
\hline D & 9 & $89.52 \pm 39.24$ & $17.32 \pm 1.38$ & $2.65 \pm 0.34$ & $4.98 \pm 0.78$ & $48.35 \pm 5.61$ & $26.06 \pm 6.25$ & $0.64 \pm 0.44$ & $0.02 \pm 0.01$ & $0.27 \pm 0.07$ \\
\hline
\end{tabular}



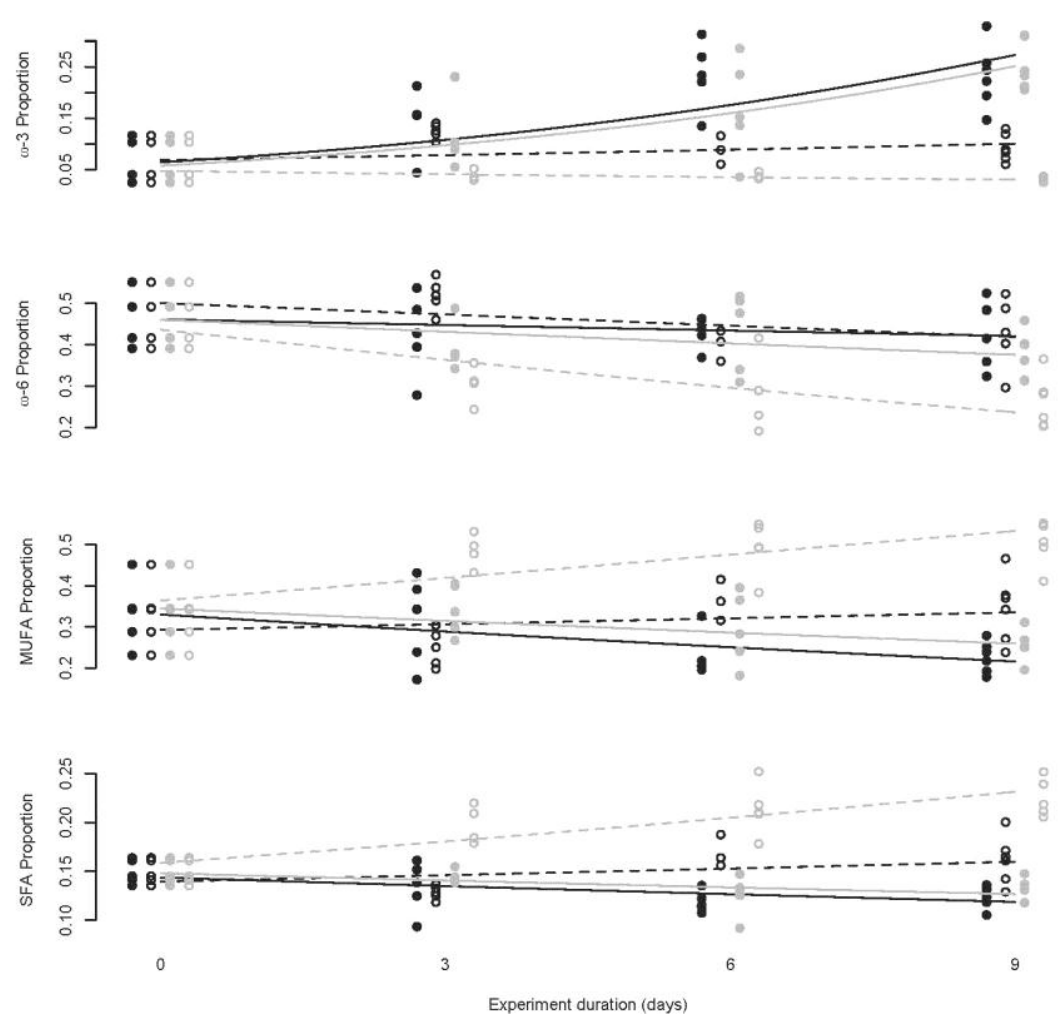

Figure 1. Modification of the proportion of various larval FA categories during the experiment under various food treatments (A: black filled dots and solid lines, B: black empty dots and dashed lines, C: grey filled dots and solid lines, D: grey empty dots and dashed lines)
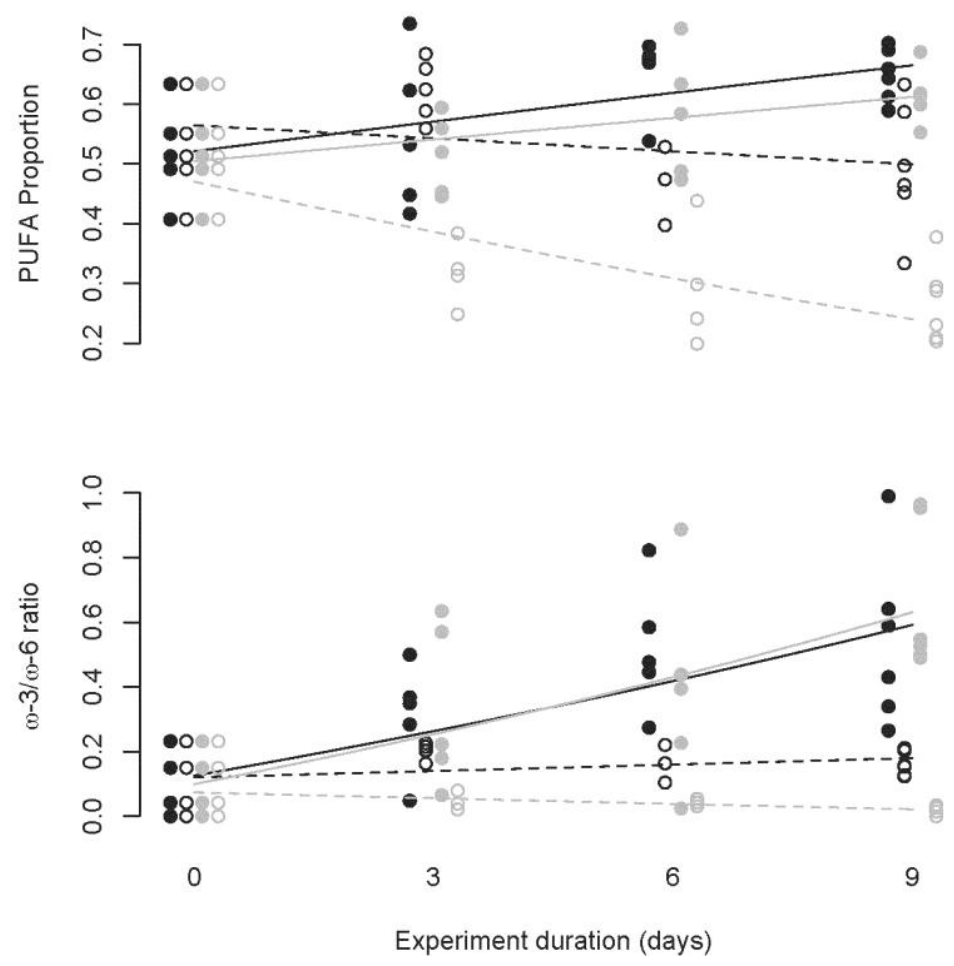

Figure 2. Modification of the larval PUFA proportion and the $\omega-3 / \omega-6$ ratio during the experiment under various food treatments (A: black filled dots and solid lines, B: black empty dots and dashed lines, C: grey filled dots and solid lines, D: grey empty dots and dashed lines) 


\section{Discussion}

In this study, we investigated how the lipid composition of mealworm larvae may shift through a modification of dietary FA composition and concentration applied for a short period of time. We provided mealworm larvae with diets differing in FA concentration (0.6-25\%) and composition. The dietary ratio of alpha-linolenic acid (ALA,

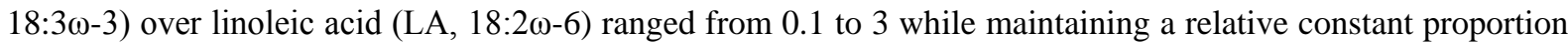
of PUFAs (0.71-0.87\%, table 1$)$.

We showed that FA compositions of mealworm larvae significantly changed after only nine days (fig. 1). A rapid integration of FAs into triglycerides, which represent approximately $90 \%$ of all lipid stored in insect (Arrese \& Soulages, 2010; Bailey, 1975; Canavoso et al., 2001), may explain this plasticity. Modifications in FA composition were mostly caused by changes in the proportion of ALA, which showed greater shifts than any other kind of FA (fig. 1, table 3). Such plasticity in the storage of $\omega$-3 PUFAs has already been reported in other insects species such as the Jamaican field cricket (Gryllus assimilis) and the giant mealworm larva (Zophobas atratus) (Komprda et al., 2013). In contrast to $\omega-3$, the proportion of $\omega-6$ appeared more stable (fig. 1). Indeed, with a similar proportion of $\omega-3$ and $\omega-6$, the model did not predict significant changes of $\omega-6$ in the course of the experiment (table 3).

The higher ALA plasticity could be explained by an imbalance in the larval $\omega-3 / \omega-6$ ratio at the beginning of the experiment. Indeed, at the start and even after the measured changes, LA remained one of the principal types of FAs, with a higher proportion than ALA (fig. 2 and table 4). Mealworm larvae were reared on slices of bread before the experiment and dietary $\omega-6$ proportions should have been high (https://ndb.nal.usda.gov). Alternatively, the high proportion of LA could be accounted for if the mealworm larvae expressed delta12-desaturase and were able to produce LA de novo (Fraenkel \& Blewett, 1947). In an environment such as wheat flour containing negligible amounts of dietary $\omega-3$, insect larvae may thus rely on LA to fulfill their need for PUFAs. As shown in our study, the larva's whole PUFA proportion increased in presence of $\omega-3$, even with the reduction in LA (table 3). Such changes highlight the assumed importance of PUFAs, and especially $\omega-3$, for insect larval development.

Finally, larvae in all treatments were heavier as the experiment progressed (table 4). However, we found significant treatment-related variation neither in mass gain (interaction between treatments and experiment duration: $\mathrm{F}=1.54, \mathrm{DF}=3,70, \mathrm{P}=0.211$ ), nor in the content of $\mathrm{FA}$ in the body (interaction between treatments and experiment duration after controlled for body mass: $\mathrm{F}=1.77, \mathrm{DF}=3,69, \mathrm{P}=0.160$ ). Our treatments may consequently not have influenced the fat and protein contents of the mealworm larvae. Further studies are required to investigate those aspects.

In conclusion, mealworm larvae revealed significant plasticity in lipid composition. High dietary $\omega-3 / \omega-6$ ratios induced an increase in PUFA proportions and in $\omega-3 / \omega-6$ ratios in larvae. Mealworm larvae and insects in general are being increasingly viewed as potential sources of protein and fat for animal and human diets. Providing flax seeds or other $\omega$-3-rich seeds to mealworm larvae could allow the food industry, at negligible cost, to produce animal fat containing healthier PUFA proportions $(>0.6)$ and $\omega-3 / \omega-6$ ratios $(>0.5)$.

\section{Acknowledgments}

This project was funded by the Swiss National Science Foundation [grants P2BEP3_168709 to NF and 31003A-159600 to PC], by the University of Fribourg and by the Polish National Science Centre [DEC-2013/10/E/NZ8/00725 to IR]. We would also like to thank Zuzanna Halat for her assistance in the maintenance of the mealworms and Sebastien Pellaud for assistance in the lab. We are also grateful to Mariana Cruz-Petersen and Santiago Cruz-Petersen for proofreading this paper for language. Finally, we thank Gerald van den Boogaart, for his advice on statistical analysis. None of the authors were subject to any conflict of interest.

\section{References}

Arnold, W., Giroud, S., Valencak, T. G., \& Ruf, T. (2015). Ecophysiology of Omega Fatty Acids: A Lid for Every Jar. Physiology, 30(3), 232-240. https://doi.org/10.1152/physiol.00047.2014

Arrese, E. L., \& Soulages, J. L. (2010). Insect Fat Body: Energy, Metabolism, and Regulation. Annual Review of Entomology, 55(1), 207-225. https://doi.org/10.1146/annurev-ento-112408-085356

Attaman, J. A., Toth, T. L., Furtado, J., Campos, H., Hauser, R., \& Chavarro, J. E. (2012). Dietary fat and semen quality among men attending a fertility clinic. Human Reproduction (Oxford, England), 27(5), 1466-1474. https://doi.org/10.1093/humrep/des065 
Bailey, E. (1975). Biochemistry of Insect Flight. In D. J. Candy \& B. A. Kilby (Eds.), Insect Biochemistry and Function (pp. 90-176).

Belluco, S., Losasso, C., Maggioletti, M., Alonzi, C. C., Paoletti, M. G., \& Ricci, A. (2013). Edible Insects in a Food Safety and Nutritional Perspective: A Critical Review. Comprehensive Reviews in Food Science and Food Safety, 12(3), 296-313. https://doi.org/10.1111/1541-4337.12014

Bradbury, J. (2011). Docosahexaenoic Acid (DHA): An Ancient Nutrient for the Modern Human Brain. Nutrients, 3(12), 529-554. https://doi.org/10.3390/nu3050529

Brandstetter, B., \& Ruther, J. (2016). An insect with a delta-12 desaturase, the jewel wasp Nasonia vitripennis, benefits from nutritional supply with linoleic acid. Naturwissenschaften, 103(5-6), 40. https://doi.org/10.1007/s00114-016-1365-0

Bucher, H. C., Hengstler, P., Schindler, C., \& Meier, G. (2002). N-3 polyunsaturated fatty acids in coronary heart disease: a meta-analysis of randomized controlled trials. The American Journal of Medicine, 112(4), 298-304.

Budge, S. M., Iverson, S. J., \& Koopman, H. N. (2006). Studying trophic ecology in marine ecosystems using fatty acids: a primer on analysis and interpretation. Marine Mammal Science, 22(4), 759-801. https://doi.org/10.1111/j.1748-7692.2006.00079.x

Burr, G. O., \& Burr, M. M. (1930). On the nature and role of the fatty acids essential in nutrion. Journal of Biological Chemistry, 86(2), 587-621.

Canavoso, L. E., Jouni, Z. E., Karnas, K. J., Pennington, J. E., \& Wells, M. A. (2001). Fat metabolism in insects. Annual Review of Nutrition, 21, 23-46. https://doi.org/10.1146/annurev.nutr.21.1.23

Chakravorty, J., Ghosh, S., \& Meyer-Rochow, V. B. (2011). Chemical Composition of Aspongopus nepalensis Westwood 1837 (Hemiptera; Pentatomidae), a Common Food Insect of Tribal People in Arunachal Pradesh (India) . Int J Vitam Nutr Res, 81(1), 1-14.

Cordain, L., Eaton, S. B., Sebastian, A., Mann, N., Lindeberg, S., Watkins, B. A., et al. (2005). Origins and evolution of the Western diet: health implications for the 21st century. The American Journal of Clinical Nutrition, 81(2), 341-354.

Cripps, C., Blomquist, G. J., \& de Renobales, M. (1986). De novo biosynthesis of linoleic acid in insects. Biochimica Et Biophysica Acta (BBA) - Lipids and Lipid Metabolism, 876(3), 572-580. https://doi.org/10.1016/0005-2760(86)90046-9

Daniels, J. L., Longnecker, M. P., Rowland, A. S., \& Golding, J. (2004). Fish Intake During Pregnancy and Early Cognitive Development of Offspring. Epidemiology, 15(4), 394-402. https://doi.org/10.1097/01.ede.0000129514.46451.ce

Engqvist, L. (2005). The mistreatment of covariate interaction terms in linear model analyses of behavioural and evolutionary ecology studies. Animal Behaviour, 70(4), 967-971. https://doi.org/10.1016/j.anbehav.2005.01.016

Estienne, M. J., Harper, A. F., \& Crawford, R. J. (2008). Dietary supplementation with a source of omega-3 fatty acids increases sperm number and the duration of ejaculation in boars. Theriogenology, 70(1), 70-76. https://doi.org/10.1016/j.theriogenology.2008.02.007

Fair, S., Doyle, D. N., Diskin, M. G., Hennessy, A. A., \& Kenny, D. A. (2014). The effect of dietary n-3 polyunsaturated fatty acids supplementationof rams on semen quality and subsequent quality of liquid stored semen. Theriogenology, 81(2), 210-219. https://doi.org/10.1016/j.theriogenology.2013.09.002

Fox, F. \& Weisberg, S. (2011). An \{R\}Companion to Applied Regression, Second Edition. Thousand Oaks CA: Sage. http://socserv.socsci.mcmaster.ca/jfox/Books/Companion

Fraenkel, G., \& Blewett, M. (1947). Linoleic acid and arachidonic acid in the metabolism of two insects, Ephestia kuehniella (Lep.) and Tenebrio molitor (Col.). The Biochemical Journal, 41(3), 475-478.

Freeman, M. P. (2000). Omega-3 fatty acids in psychiatry: a review. Annals of Clinical Psychiatry : Official Journal of the American Academy of Clinical Psychiatrists, 12(3), 159-165.

Geiser, F., \& Kenagy, G. J. (1987). Polyunsaturated lipid diet lengthens torpor and reduces body temperature in a hibernator. The American Journal of Physiology, 252(5 Pt 2), R897-901.

Halloran, A., \& Vantomme, P. (2013). The contribution of insects to food security, livelihoods and the 
environment. Food and Agriculture Organization of the United Nations. Retrieved from http://www.fao.org/edible-insects/en/

Harper, C. R., \& Jacobson, T. A. (2003). Beyond the Mediterranean diet: the role of omega-3 Fatty acids in the prevention of coronary heart disease. Preventive Cardiology, 6(3), 136-146.

Hulbert, A. J. (2010). Metabolism and longevity: Is there a role for membrane fatty acids? Integrative and Comparative Biology, 50(5), 808-817. https://doi.org/10.1093/icb/icq007

Jump, D. B. (2002). The Biochemistry of n-3 Polyunsaturated Fatty Acids. Journal of Biological Chemistry, 277(11), 8755-8758. https://doi.org/10.1074/jbc.R100062200

Jørgensen, M. H., Hernell, O., Hughes, E., \& Michaelsen, K. F. (2001). Is there a relation between docosahexaenoic acid concentration in mothers' milk and visual development in term infants? Journal of Pediatric Gastroenterology and Nutrition, 32(3), 293-296.

Komprda, T., Zorníková, G., Rozíková, V., Borkovcová, M., \& Przywarová, A. (2013). The effect of dietary Salvia hispanica seed on the content of n-3 long-chain polyunsaturated fatty acids in tissues of selected animal species, including edible insects. Journal of Food Composition and Analysis, 32(1), 36-43. https://doi.org/10.1016/j.jfca.2013.06.010

McGuire, L. P., Fenton, M. B., \& Guglielmo, C. G. (2013). Phenotypic flexibility in migrating bats: seasonal variation in body composition, organ sizes and fatty acid profiles. The Journal of Experimental Biology, 216(Pt 5), 800-808. https://doi.org/10.1242/jeb.072868

Meyer-Rochow, V. B., \& Changkija, S. (1997). Uses of insects as human food in Papua New Guinea, Australia, and North-East India: Cross-cultural considerations and cautious conclusions. Ecology of Food and Nutrition, 36(2-4), 159-185. https://doi.org/10.1080/03670244.1997.9991513

Mischoulon, D., \& Fava, M. (2000). Docosahexanoic acid and omega-3 fatty acids in depression. The Psychiatric Clinics of North America, 23(4), 785-794.

Mlcek, J., Rop, O., Borkovcová, M., \& Bednarova, M. (2014). A comprehensive look at the possibilities of edible insects as food in Europe - a Review. Polish Journal of Food and Nutrition Sciences, 64(3), 147-157. https://doi.org/10.2478/v10222-012-0099-8

Mourvaki, E., Cardinali, R., Bosco, A. D., Corazzi, L., \& Castellini, C. (2010). Effects of flaxseed dietary supplementation on sperm quality and on lipid composition of sperm subfractions and prostatic granules in rabbit. The , 73(5), 629-637. https://doi.org/10.1016/j.theriogenology.2009.10.019

Munro, D., \& Thomas, D. W. (2004). The role of polyunsaturated fatty acids in the expression of torpor by mammals: a review. Zoology, 107(1), 29-48. https://doi.org/10.1016/j.zool.2003.12.001

Nowak, V., Persijn, D., Rittenschober, D., \& Charrondiere, U. R. (2016). Review of food composition data for edible insects. Food Chemistry, 193, 39-46. https://doi.org/10.1016/j.foodchem.2014.10.114

Rahman, M. M., Gasparini, C., Turchini, G. M., \& Evans, J. P. (2014). Experimental reduction in dietary omega-3 polyunsaturated fatty acids depresses sperm competitiveness. Biology Letters, 10(9), 20140623-20140623. https://doi.org/10.1098/rspb.2003.2656

Rumpold, B. A., \& Schlüter, O. K. (2013a). Nutritional composition and safety aspects of edible insects. Molecular Nutrition \& Food Research, 57(5), 802-823. https://doi.org/10.1002/mnfr.201200735

Rumpold, B. A., \& Schlüter, O. K. (2013b). Potential and challenges of insects as an innovative source for food and feed production. Innovative Food Science and Emerging Technologies, 17(C), 1-11. https://doi.org/10.1016/j.ifset.2012.11.005

Safarinejad, M. R., Hosseini, S. Y., Dadkhah, F., \& Asgari, M. A. (2010). Relationship of omega-3 and omega-6 fatty acids with semen characteristics, and anti-oxidant status of seminal plasma: a comparison between fertile and infertile men. Clinical Nutrition (Edinburgh, Scotland), 29(1), 100-105. https://doi.org/10.1016/j.clnu.2009.07.008

Simopoulos, A. P. (1999). Evolutionary aspects of omega-3 fatty acids in the food supply. Prostaglandins, Leukotrienes, and Essential Fatty Acids, 60(5-6), 421-429.

Simopoulos, A. P. (2002). The importance of the ratio of omega-6/omega-3 essential fatty acids. Biomedicine \& Pharmacotherapy = Biomédecine \& Pharmacothérapie, 56(8), 365-379.

Sinclair, H. (1984). Essential fatty acids in perspective. Human Nutrition. Clinical Nutrition, 38(4), 245-260. 
Stanley, D. W., \& Miller, J. S. (2006). Eicosanoid actions in insect cellular immune functions. Entomologia Experimentalis Et Applicata, 119, 1-13.

Stanley-Samuelson, D. W., Jensen, E., Nickerson, K. W., Tiebel, K., Ogg, C. L., \& Howard, R. W. (1991). Insect immune response to bacterial infection is mediated by eicosanoids. Proceedings of the National Academy of Sciences of the United States of America, 88(3), 1064-1068.

Strzeżek, J., Fraser, L., Kuklińska, M., Dziekońska, A., \& Lecewicz, M. (2004). Effects of dietary supplementation with polyunsaturated fatty acids and antioxidants on biochemical characteristics of boar semen., 4(3), 271-287. Retrieved from http://eutils.ncbi.nlm.nih.gov/entrez/eutils/elink.fcgi?dbfrom=pubmed\&id=15592586\&retmode=ref\&cmd= prlinks

Uauy, R., Hoffman, D. R., Peirano, P., Birch, D. G., \& Birch, E. E. (2001). Essential fatty acids in visual and brain development. Lipids, 36(9), 885-895.

Valencak, T. G., Arnold, W., Tataruch, F., \& Ruf, T. (2003). High content of polyunsaturated fatty acids in muscle phospholipids of a fast runner, the European brown hare (Lepus europaeus). Journal of Comparative Physiology. B, Biochemical, Systemic, and Environmental Physiology, 173(8), 695-702. https://doi.org/10.1007/s00360-003-0382-4

Van den Boogaart, K. G., \& Tolosana-Delgado, R. (2013). Analyzing compositional data with R. Springer

Van den Boogaart, K. G., Tolosana, R., \& Bren, M. (2014). compositions: Compositional Data Analysis. R package version 1.10-2. URL http://CRAN. R-project. org/

Wood, J. D., Richardson, R. I., Nute, G. R., Fisher, A. V., Campo, M. M., Kasapidou, E., et al. (2004). Effects of fatty acids on meat quality: a review. Meat Science, 66(1), 21-32. https://doi.org/10.1016/S0309-1740(03)00022-6

Yang, L., Siriamornpun, S., \& Li, D. (2006). Polyunsaturated fatty acid content of edible insects in Thailand. Journal of Food Lipids.

Zalata, A. A., Christophe, A. B., Depuydt, C. E., Schoonjans, F., \& Comhaire, F. H. (1998). The fatty acid composition of phospholipids of spermatozoa from infertile patients. Molecular Human Reproduction, 4(2), 111-118.

Zhou, X.-R., Horne, I., Damcevski, K., Haritos, V., Green, A., \& Singh, S. (2008). Isolation and functional characterization of two independently-evolved fatty acid Delta12-desaturase genes from insects. Insect Molecular Biology, 17(6), 667-676. https://doi.org/10.1111/j.1365-2583.2008.00841.x

Ziboh, V. A., Miller, C. C., \& Cho, Y. (2000). Metabolism of polyunsaturated fatty acids by skin epidermal enzymes: generation of antiinflammatory and antiproliferative metabolites. The American Journal of Clinical Nutrition.

\section{Copyrights}

Copyright for this article is retained by the author(s), with first publication rights granted to the journal.

This is an open-access article distributed under the terms and conditions of the Creative Commons Attribution license (http://creativecommons.org/licenses/by/4.0/). 